\title{
O DESENVOLVIMENTO DA INFRAESTRUTURA PORTUÁRIA DE PARANAGUÁ/PR PARA O FOMENTO DO COMERCIO EXTERIOR
}

\author{
ARTIGO ORIGINAL \\ IUNKLAUS, Leandro Michel ${ }^{1}$ \\ JUNIOR, Mauro Fernandes ${ }^{2}$ \\ CARVALHO, Luiz Fernando Melo de ${ }^{3}$
}

IUNKLAUS, Leandro Michel. JUNIOR, Mauro Fernandes. CARVALHO, Luiz Fernando Melo de. $\mathbf{O}$ desenvolvimento da infraestrutura portuária de Paranaguá/PR para o fomento do comercio exterior. Revista Científica Multidisciplinar Núcleo do Conhecimento. Ano 04, Ed. 10, Vol. 04, pp. 130-156. Outubro de 2019. ISSN: 24480959, Link de acesso: https://www.nucleodoconhecimento.com.br/administracao/infraestruturaportuaria

\section{RESUMO}

O mundo cada vez mais globalizante estreitou as barreiras de comércio e fez com que as relações comerciais ficassem mais fáceis no cenário do comércio exterior. Diante desta perspectiva moderna de relação transnacional, o presente estudo visa constatar de que forma o desenvolvimento do porto de Paranaguá influi no comércio exterior do estado do Paraná. Para tanto, investigará como é atualmente a operação do Porto de Paranaguá, analisando as diretrizes sugeridas pelo PDZPO e apontando as melhorias de infraestrutura que podem ser realizadas, constatando os possíveis benefícios

\footnotetext{
${ }^{1}$ Graduando em Curso Superior Tecnólogo em Gestão Portuária.

${ }^{2}$ Graduando em Curso Superior Tecnólogo em Gestão Portuária.

${ }^{3}$ Graduação em Economia. Especialização em Planejamento Estratégico e Gestão de Negócios.
} 
gerados pela modernização do porto de Paranaguá - PR. Viabilizando este estudo, o método empregado para a coleta de dados nesta pesquisa aplicada foi o da pesquisa bibliográfica acerca do tema proposto, com a análise qualitativa dos achados. A partir dos dados conquistados foi possível entender que as inovações do porto de Paranaguá decorrem de sua administração e que esses avanços tecnológicos propostos servem para manter a competitividade do porto no mercado externo em médio e longo prazo. Enfim, por meio do estudo realizado concluiu-se que sem a modernização do porto de Paranaguá sua competitividade estará comprometida frente ao cenário mundial do comercio exterior, sendo necessários investimentos a médio e longo prazo diuturnos para manter sua relevância comercial.

Palavras-chave: plano de desenvolvimento, Zoneamento de Porto Organizado PDZPO, modernização, complexo portuário.

\section{INTRODUÇÃO}

Diante de um mercado cada vez mais global e massivamente capitalizado, a compra e venda de produtos entre as empresas dos países é preponderante para a economia mundial. Assim, é importante pensar em alternativas para melhorar e dinamizar as estruturas que viabilizem o escoamento da produção de um país e remessa a outro, com custos competitivos e tempos menores, contribuindo para a competitividade, tanto das empresas nacionais, quanto da política externa do país.

Neste contexto, esta pesquisa visa entender de que forma o desenvolvimento tecnológico e de infraestrutura do porto da cidade de Paranaguá, estado do Paraná, auxilia para o comércio exterior do estado, otimizando esta competitividade das empresas nacionais. O estudo contribui para um entendimento conciso de quais são as políticas que necessitam ser empregadas de acordo com o Plano de Desenvolvimento e Zoneamento Portuário (PDZPO) para a melhoria do escoamento de produção e salienta de que forma estas políticas podem ser implementadas para que o comércio exterior dos produtos escoados seja agressivo. 
Com a emancipação do Estado, Curitiba foi escolhida como capital. Paranaguá poderia ter sido a eleita, entretanto, em meio a inúmeros interesses das classes dominantes sobressaiu sua imagem de cidade "suja" e "cheia de doenças" - um dos motivos alegados para ter sido preterida. Após perder seu papel na organização política da região sul do Brasil, Paranaguá, que passou a se autodenominar "Princesa do Litoral", viu-se esvaziada e passou a ter no Porto e na vida cultural já estabelecida, sua sustentação (ABRAHÃO, 2011, p. 39).

Para tanto, como objetivo geral, a pesquisa se debruça em constatar de que forma este desenvolvimento da infraestrutura do porto de Paranaguá influi no comércio exterior do estado do Paraná. Especificadamente, os objetivos são pautados em investigar como é a operação, atualmente, no Porto de Paranaguá, analisando as diretrizes do PDZPO, de forma a apontar as melhorias que poderiam ser implementadas. Visa, ainda, demonstrar como estas melhorias contribuem para o comércio exterior do estado do Paraná, e, por fim, quais os benefícios que a modernização do porto proporcionaria.

A pesquisa tem natureza aplicada, com um método hipotético-dedutivo. Os objetivos do estudo são exploratórios e explicativos. Por meio destas técnicas, os dados serão levantados por pesquisa bibliográfica e estudo de caso. Assim, os dados coletados terão abordagem qualitativa, quando provenientes do método bibliográfico e; quantitativo quando provenientes do procedimento de estudo de caso.

A pesquisa se pautará em analisar de que forma os avanços de desenvolvimento do Porto de Paranaguá influem na política de comércio exterior do estado do Paraná. Para tanto, buscar-se-á no, por meios dos materiais, dados e informações buscadas, responder à seguinte problemática: de que forma o desenvolvimento da infraestrutura dos píeres e berços de atracamento do porto de Paranaguá contribui para o comércio exterior do estado do Paraná?

O objetivo geral visa investigar de que forma o desenvolvimento da infraestrutura do Porto de Paranaguá contribui para escoar a produção do país, analisando como isto reflete no comércio exterior do estado do Paraná. Especificadamente, a pesquisa 
investigará como é atualmente a operação do Porto de Paranaguá, analisando as diretrizes sugeridas pelo PDZPO e apontando as melhorias de infraestrutura que podem ser realizadas, de modo a demonstrar como estas melhorias de infraestrutura contribuem para o comércio exterior do estado do Paraná, constatando os possíveis benefícios gerados pela modernização do porto de Paranaguá - PR.

A hipótese de pesquisa é que a dificuldade de escoar a produção no Porto de Paranaguá pode ser resolvida com o desenvolvimento e modernização da infraestrutura dos píeres de atracação. Além, é hipótese de pesquisa que o Porto de Paranaguá é preponderante à política de exportação promovida pelo estado do Paraná, sendo imprescindível sua modernização, em consonância com as diretrizes estabelecidas pela legislação vigente no país.

Em relação à metodologia empregada, quanto à sua natureza, a pesquisa é aplicada e o método escolhido para conseguir os dados é o hipotético-dedutivo. Já os objetivos do estudo se classificam como exploratórios quando da análise dos dados coletados pela pesquisa bibliográfica e explicativa quando da análise dos dados coletados pelo estudo de caso proposto. Os dados coletados pelo procedimento bibliográfico terão tratamento qualitativo, já aqueles dados coletados pelo estudo de caso, que requeiram tabulação e análise objetiva, terão tratamento quantitativo.

Neste sentido, a pesquisa proporciona à comunidade acadêmica formas de aplicar o conhecimento aprendido teoricamente à prática da gestão portuária e, consequente, desenvolvimento de seus atributos. Também, para os profissionais que desempenham suas tarefas de gestão no porto, o estudo traz à tona formas de implementar as melhorias sugeridas pelo PDZPO.

Os achados da pesquisa visam demonstrar meios exequíveis de melhoramento da infraestrutura portuária com vias de investigar de que forma estes avanços contribuem para o comércio exterior do estado do Paraná. Também, contribui para que haja clareza na tomada de decisões, principalmente ao que tange ao desenvolvimento tecnológico do porto. 


\section{METODOLOGIA}

A metodologia do trabalho científico está pautada na melhor condução da produção científica e acadêmica, proporcionando ao pesquisador uma padronização na forma como os dados serão coletados e interpretados e, ainda, de que forma os objetivos da pesquisa serão atingidos (PRODANOV e FREITAS, 2013). Nesta perspectiva, a definição da metodologia é ímpar para o efetivo descobrimento e desenvolvimento do estudo ora proposto.

Desta forma, em consonância com o que apregoa Severino (2007), quanto à sua natureza, a pesquisa é aplicada, uma vez que os conhecimentos gerados a partir dos achados serão dirigidos à solução de um problema específico. O método escolhido para conseguir os dados é o hipotético-dedutivo. Este método, de acordo com o autor retro citado, contribui para a elaboração de premissas hipotéticas, que serão validadas, ou não, a depender dos testes realizados.

Os objetivos do estudo se classificam como exploratórios, ou seja, há construção de hipóteses a partir dos problemas propostos (MARCONI e LAKATOS, 2013). Contudo, a pesquisa também é explicativa no que tange aos objetivos quando analisado o estudo do caso analisado; isto porque, conforme Marconi e Lakatos (2017) é explicativa a pesquisa que identifica aqueles fatos relevantes e os conhece sob a perspectiva da realidade.

Quanto ao procedimento empregado à coleta de dados, a pesquisa é bibliográfica. Busca, portanto, em livros, jornais, revistas, periódicos, artigos científicos e na rede mundial de computadores informações que contribuam para o desenvolvimento dos conceitos teóricos e práticos que envolvem o estudo (YIN, 2011). Somados a este procedimento, têm-se seu caráter procedimental documental, já que busca em documentos históricos, produzidos ou não pelo objeto do estudo, formas de entender os fatores estudados.

Além da coleta dos dados por meio da pesquisa bibliográfica, a pesquisa se valerá de um estudo de caso, conduzido no porto da cidade de Paranaguá, estado do Paraná. 
Assim, de acordo com Prodanov e Freitas (2013), este procedimento de coleta de dados demonstra trazer ao estudo as formas pelas quais os dados pesquisados acontecem e se promovem no mundo fático, analisando-os dentro de seu contexto real de desenvolvimento.

Quanto à abordagem dos dados coletados pelos procedimentos técnicos, estes terão tratamento qualitativo e quantitativo. Os dados coletados pelo procedimento bibliográfico terão tratamento qualitativo, pois faz-se uso da interpretação subjetiva pelo pesquisador dos dados achados. Já aqueles dados coletados pelo estudo de caso, que requeiram tabulação e análise objetiva, terão tratamento quantitativo, valendo-se a pesquisa da interpretação dos números e estatísticas gerados (GIL, 2013).

\section{RESULTADOS E DISCUSSÕES}

A atividade portuária exerce preponderante importância no arranjo organizacional urbano, geográfico e econômico da cidade de Paranaguá, desde a sua concepção até os dias atuais, com políticas voltadas ao comércio externo e à modernização das formas de escoar a produção interna do estado do Paraná. Este processo da atuação e do protagonismo do Porto de Paranaguá remonta ao século XIX, ligado intimamente à ocupação e povoamento das margens do Rio Itiberê, dando formação ao hoje conhecido centro histórico. Em consequência deste crescimento e importância geográfica ímpar, Paranaguá se tornou a capital da então província do Paraná, ainda ligado ao estado de São Paulo (GODOY, 1998).

Contudo, em 1853, de acordo com as pesquisas de Scheifer (2008, p. 25), a capital fora movida para Curitiba, sob o argumento de que, além de outros, a nova capital proporcionaria "um clima mais ameno" e que "deste lado da província não há [...] a irritação dos partidos políticos". As justificativas dadas à época evidenciavam que, embora Paranaguá fosse importante e um reduto estratégico para a formação econômica do Paraná, a localização da nova capital era contemplada por localização que privilegiava a possibilidade de controle do interior da província. 
Embora houvesse a mudança, a cooperação para a manutenção tática de Paranaguá como força motriz econômica da época era latente, já que ligar a nova capital Curitiba à Paranaguá se mostrou a prioridade do governo, estabelecendo projetos arrojados de ferrovias que realizassem a ligadura entre o litoral e o interior. A ferrovia foi importante e causou impactos em Paranaguá, modificando sua estrutura organizacional urbana e política, trazendo mais circulação de pessoas e materiais devido ao escoamento da produção (HARVEY, 2005).

Com o avançar da história, o estado do Paraná se tornara um importante exportador de madeira, o que requereu adaptações na infraestrutura portuária de Paranaguá, sobretudo naquelas concernentes ao acesso de grandes embarcações. Assim, em 1930 foram inauguradas as novas instalações modernizadas e ampliadas do Porto de Paranaguá, marcada pela forte crise brasileira do setor exportador agrário, resultado e reflexo da Crise de 1929, que culminou em uma completa derrocada do crescimento que o porto havia tido até então (TRINTIN, 2001).

Recuperando-se, a economia agrária brasileira pautada quase que exclusivamente na produção cafeicultora, em 1940 dá ao Estado do Paraná condição de principal produtor da cultura no país. Esta mudança da perspectiva do eixo paulista para o paranaense da cultura cafeicultora fora decisiva para que o porto de Paranaguá recebesse substanciais incentivos financeiros e de investimento em infraestrutura para suportar a intensa exportação cafeeira que se inaugurava. Além das modificações profundas portuárias, dinamização do escoamento pela construção da Rodovia do Cerne e da movimentação constante do porto de Paranaguá, a cidade se modificara em consequência da demanda de estruturas de suporte comercial e da necessidade de mão-de-obra para o desempenho dos trabalhos, tanto nos serviços de infraestrutura, quanto no próprio porto (GODOY, 1998).

A relação social técnica-meio torna possível perceber que as mudanças trouxeram como decorrência ao menos duas fontes de pressão sobre o ambiente urbano de Paranaguá já no século XIX. A primeira delas se relaciona à necessidade de infraestrutura, oferta de energia elétrica, estrutura viária (de transporte urbano e interurbano) e de comunicação. O que se vincula ao exercício das atividades portuárias, direta ou indiretamente. Por outro lado, a própria atração de novos trabalhadores 
gerou demandas relacionadas ao crescimento da população, resultando em desequilíbrios sociais e novas pressões urbanas, em termos de serviços públicos e moradia (ABRAHÃO, 2011, p. 42).

Conforme aduz o autor acima citado, as profundas transformações urbanas da cidade da Paranaguá estão diametralmente interligadas às atividades de expansão portuária e às necessidades de melhorias no escoamento constante da produção, à época cafeeira. Neste sentido, o autor ainda deixa claro que o Estado tomou ações afirmativas para conter o avanço desordenado da cidade, visando a contenção de proliferação de doenças e melhorando as condições sanitárias básicas da população, implantando políticas de saneamento.

Para Trintin (2001), a economia do Paraná volta a crescer de forma significativa nos anos 1960, marcada pela industrialização e ocasionando modificações na logística portuária de Paranaguá. A melhoria da malha viária para o escoamento da produção proporcionou que o café pudesse ser beneficiado diretamente na região produtora, o que impactou diretamente nas atividades como armazenagem, embalagem e outros processos relacionado à cadeia produtiva do café. Contudo, embora estes postos de trabalho correlatos à atividade do café estivessem extintos a cidade de Paranaguá continuou a atrair novos ciclos migratórios e, de acordo com o IBGE, a população da cidade em 1960 já havia crescido em torno de $46 \%$ nos últimos 10 anos, o que faria com que Paranaguá continuasse a crescer e a ocupar, em 1970, a quarta maior densidade urbana paranaense.

Contudo, os tempos de ouro do café se esgotaram e deram lugar aos ciclos de novos grãos. Neste contexto, houve "redução da ordem de $67 \%$ da mão-de-obra ligada a atividade portuária de exportação do café, sendo que o complexo-grãos não foi capaz de absorver tal contingente" (GODOY, 1998, p, 122), o que significa dizer que o perfil ocupacional espacial urbano da cidade da Paranaguá se modificava à proporção que os postos de trabalhos eram extintos e os espaços ociosos do porto passaram a ser utilizados por multinacionais para armazenagem e movimentação de cargas.

Mais tarde, a década de 1990 traria uma forte industrialização ao estado do Paraná, sobretudo à região de capital Curitiba e de sua região metropolitana, requerendo que 
a capacidade de escoamento de produção e que a demanda do porto de Paranaguá fosse repensada. Havia forte pressão para que novas tecnologias fossem implementadas para dar vazão aos interesses do capital interno e externo, dando competitividade ao mercado brasileiro interno, proporcionando políticas mais flexíveis e permissíveis.

Reiteradamente, a relação entre a baixa inserção do Brasil no comércio internacional passou a ser relacionada, através do discurso hegemônico, à baixa competitividade dos portos brasileiros. Sendo que o aumento da referida competitividade implica na adoção das novas tecnologias eletrônicas, bem como o aumento da flexibilidade nas relações trabalhistas, para destacar alguns dos aspectos vinculados ao processo (ABRAHÃO, 2011, p. 47).

A modernização dos portos brasileiros era necessária para que os investimentos internos e o crescimento nacional continuassem. Desta forma, investimento governamentais expressivos foram realizados como apoio à exportação e à atividade portuária em todo o Brasil. Este processo proporcionou ao setor de exportações assumir ares mais sofisticados, dando aos órgãos governamentais domínio sobre o território, as práticas de produção e seu escoamento, bem como conectar os diversos parques industriais estrategicamente alocados (HARVEY, 2006).

Dando vazão à essa necessidade de dinamização portuária e vislumbrando a necessidade de contemplar políticas cada vez mais expansionistas ao que tange ao comercio exterior brasileiro, consolidando uma economia de exportação solidificada e massificada. Atualmente o porto de Paranaguá é administrado pela Administração dos Portos de Paranaguá e Antonina (APPA), autarquia criada pelo governo do Paraná e convertida em empresa pública em 2014 (PDZPO, 2017).

No modelo landlord, entende-se que a autoridade portuária é responsável e dona da área portuária, como também pelo fornecimento da infraestrutura de acesso aquaviário, bacia de evolução, berços de atracação, acessos rodoviários e ferroviários, acessos internos, entre outros. Já a empresa privada é responsável pela superestrutura, onde são englobados os equipamentos, armazéns, pessoal e máquinas de operação, e armazenagem de mercadorias (PDZPO, 2012, p. 29). 
De acordo com as diretrizes especificadas, a autoridade portuária deve prover tanto a administração do porto, quanto condições mínimas satisfatórias de infraestruturas operacionais. Isto também visa dizer que a responsabilidade por todas as melhorias, benfeitorias, parcerias, gestão, qualidade dos serviços e toda a prestação se serviços inerentes ao porto é de responsabilidade da APPA.

Neste sentido, a Administração Portuária tem a responsabilidade de prover mecanismos basilares para que a competitividade do porto de Paranaguá evolua e se perpetue, proporcionando a absorção da demanda interna gerada e a escoando para fora do país. O empenho deve ser pautado em modernizar as estruturas e conseguir que a novas tecnologias de gesta que o comércio exterior se aperfeiçoe e assuma papel preponderante na atuação global, o que é corroborado por um mundo cada vez mais globalizante e internacionalmente competitivo (TAVARES, 2013).

Um comercio exterior fortificado é de suma importância para que a envergadura das nações, atores globais no contexto atual, se maximizem e apareçam como possíveis parceiros de negócios, nos quais há confiabilidade e os custos não exorbitem. Esta integração econômica proporcionada pelo comércio exterior faz com que haja um intercâmbio das mercadorias entre os países e, além, de suas culturas e hábitos, contribuindo para uma interdisciplinaridade e uma maximização das relações interrelacionais dali decorrentes (LUNA, 2015).

O contexto global e dinâmico da troca das informações no qual as nações e, consequentemente, seus portos estão inseridos requer da autoridade portuária um inúmeras providencias para continuar administrando e desempenhando papel importante e primordial no cenário internacional da comercialização de produtos. Para isso, a melhoria e implementação de novas abordagens tecnológicas e modernização dos portos brasileiros, incluindo o de Paranaguá, faz-se necessária e diuturna, vez que o advento contemporâneo da globalização requer rapidez na tomada das decisões e protagonismo (KEEDI, 2017).

Contudo, a realidade brasileira atual não é a ideal, tampouco ruma para que parâmetros aceitáveis de infraestruturas mínimas sejam providos ao comércio 
internacional de produtos, principalmente através dos portos. Em classificação de 2017 dada pela Câmara de Comércio Internacional, organização voltada ao comércio e que abrange associações e empresas ao redor do mundo todo, o Brasil ocupa a 69a posição de um total de 75 países pesquisados.

Em uma escala de 0 a 6 , onde são calculados diversos fatores como tecnologia empregada no setor, segurança na atuação e manejo das mercadorias, a nota brasileira ficou em 2,4, o que é irrisório perto de sua atuação e importância de geolocalização estratégica na América do Sul, encabeçando o bloco econômico Mercosul (KOJIKOVSKI, 2017).

Em certo ponto, na contramão do ritmo brasileiro e no contexto paranaense, segundo dados da APPA, o ano de 2017 fora marcado por um forte crescimento do comercio externo do porto de Paranaguá. Em relação a 2016, em 2017 houve crescimento de $17 \%$ nas exportações operadas no porto de Paranaguá, frente ao crescimento nacional de 7,2\%, de acordo com os dados divulgados nos relatórios do Ministério da Industria, Comercio Exterior e Serviços, o que fica evidenciado no Gráfico 1.

Gráfico 1 - Cagas mais movimentadas no Porto de Paranaguá no ano de 2017

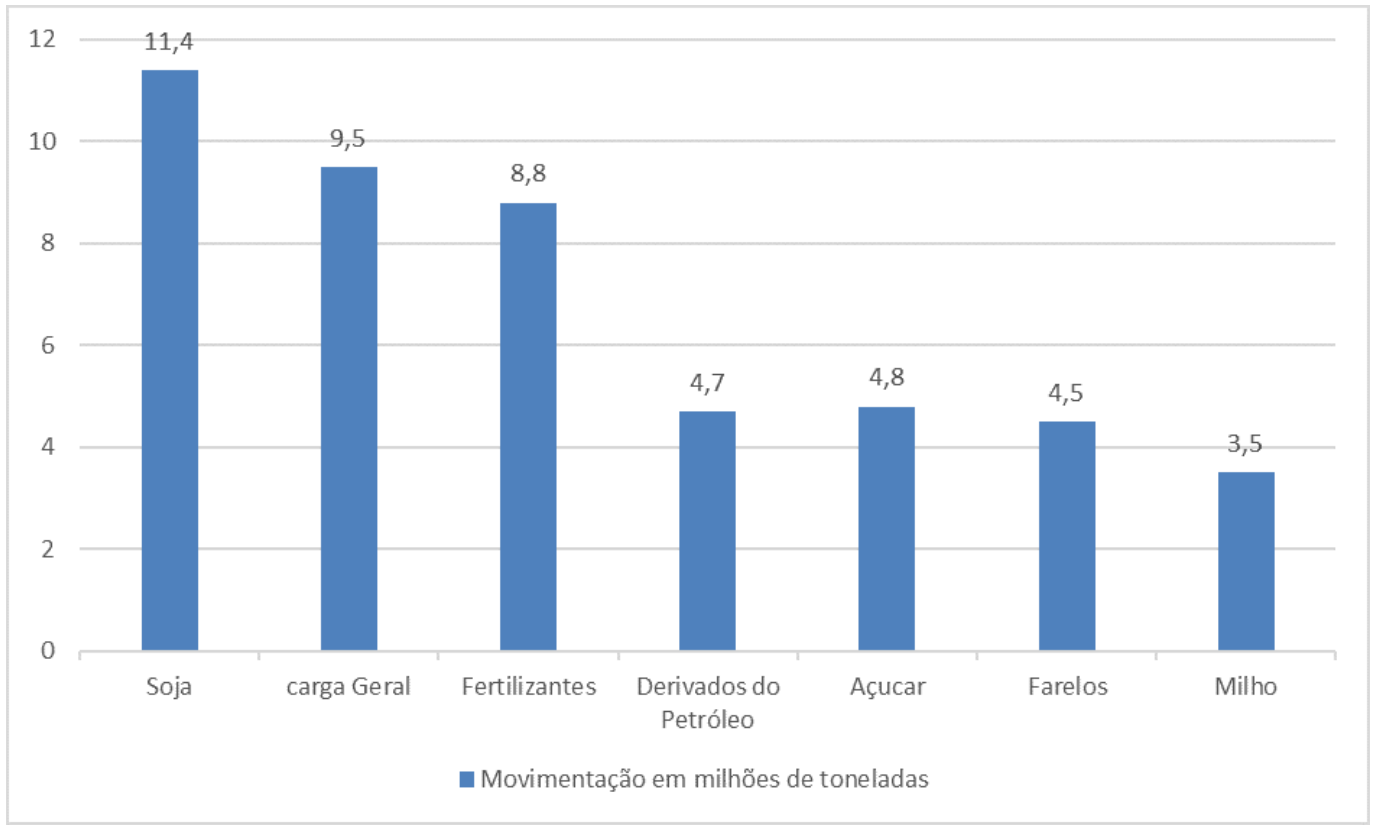

Fonte: Elaborado pelo Autor (2018), com base em APPA (2017) 
Estes dados demonstram que o porto de Paranaguá se mostra em desenvolvimento e estabelece políticas voltadas a fomentar e melhorar o comércio exterior do estado do Paraná. Este processo de modernização, embora se estabeleça lentamente, é benéfico e tem papel importante para o crescimento regional e nacional, evidenciando o fortalecimento dos portos brasileiros como artificie para uma economia mais sustentável e forte, com vias ao crescimento e competitividade frente aos avanços globais.

O Porto de Paranaguá também é um porto de grande porte com uma área de influência de 10 estados brasileiros, sendo eles: Paraná, Mato Grosso, Mato Grosso do Sul (os três como principais auxiliares em transições comerciais - US $\$ 12,49$ bilhões só do Paraná, ou $72,8 \%$ do seu comércio internacional; Mato Grosso, com movimentação de US\$ 1,09 bilhão, ou 33,3\% do seu comércio externo; e o Mato Grosso do Sul, com US $\$ 419,99$ milhões, ou 38,4\% do seu comércio internacional), São Paulo, Santa Catarina, Goiás, Minas Gerais e Rio Grande do Sul. No Porto de Paranaguá, os produtos importados são menos importantes do que os exportados, pois somente os exportados possuem uma grande diversificação, como no caso da carne, do frango, de tortas, de resíduos sólidos de soja ou da própria soja e até veículos para transportes de passageiros (SOUSA, 2016, p. 46).

Entretanto, conforme se vê no trecho acima, embora os investimentos estejam acontecendo e o porto de Paranaguá venha apresentando um crescimento e certa modernização, o que reflete o aumento da taxa de exportação de mercadorias, há fatores importantes que fazem com que a sua efetiva expansão e modernização não se concretizem. Estas diretrizes estão evidenciadas no Plano de Desenvolvimento e Zoneamento do Porto de Paranaguá (PDZPO), que consiste em estabelecer diretrizes claras e consistentes de ações que o porto deve adotar para que o seu crescimento não reste prejudicado, estabelecendo políticas que abrangem sobretudo o planejamento operacional de crescimento.

O PDZPO (2017) traz consigo propostas importantes, calçadas em decretos legislativos que tangenciam as ações das autoridades portuárias e devem ser postas em prática para o bom andamento dos trabalhos presentes e futuros. O Plano de Desenvolvimento do porto de Paranaguá discorre sobre a situação atual do porto e dá indícios e diretrizes de como as melhorias de gestão e organização operacionais 
devem ocorrer para que os investimentos portuários sejam readequados de acordo com as proposições ambientais e legislativas vigentes.

Para viabilizar o estudo de como a modernização e as inovações tecnológicas no porto de Paranaguá contribuirão para o comércio exterior do estado do Paraná é necessário entender de que forma se encontram algumas características fundamentais para a expansão e como a Plano de Desenvolvimento e Zoneamento propõe soluções. Assim, após a análise das proposições feitas pelo plano, com base nas características atuais do porto de Paranaguá, é possível vislumbrar de que forma efetivamente isto pode ser viável, sob o ponto de vista econômico e financeiro e se, efetivamente, trará impactos significativos à área do comercio de exportação do estado do Paraná.

Atualmente, de acordo com o relatório mais recente do PDZPO (2017), o porto de Paranaguá (Figura 1) conta com um cais público de extensão de $2.816 \mathrm{~m}$, o que dispõe em 14 berços de atendimento simultâneo para 12 a 14 navios. Além destes, há 1 berço de $220 \mathrm{~m}$ para atracação do tipo roll-on-roll-off ${ }^{[4]}$, dos quais possui 3 dólfins ${ }^{[5]}$ de atracação e 1 de amarração.

Figura 1 - Vista aérea do porto de Paranaguá

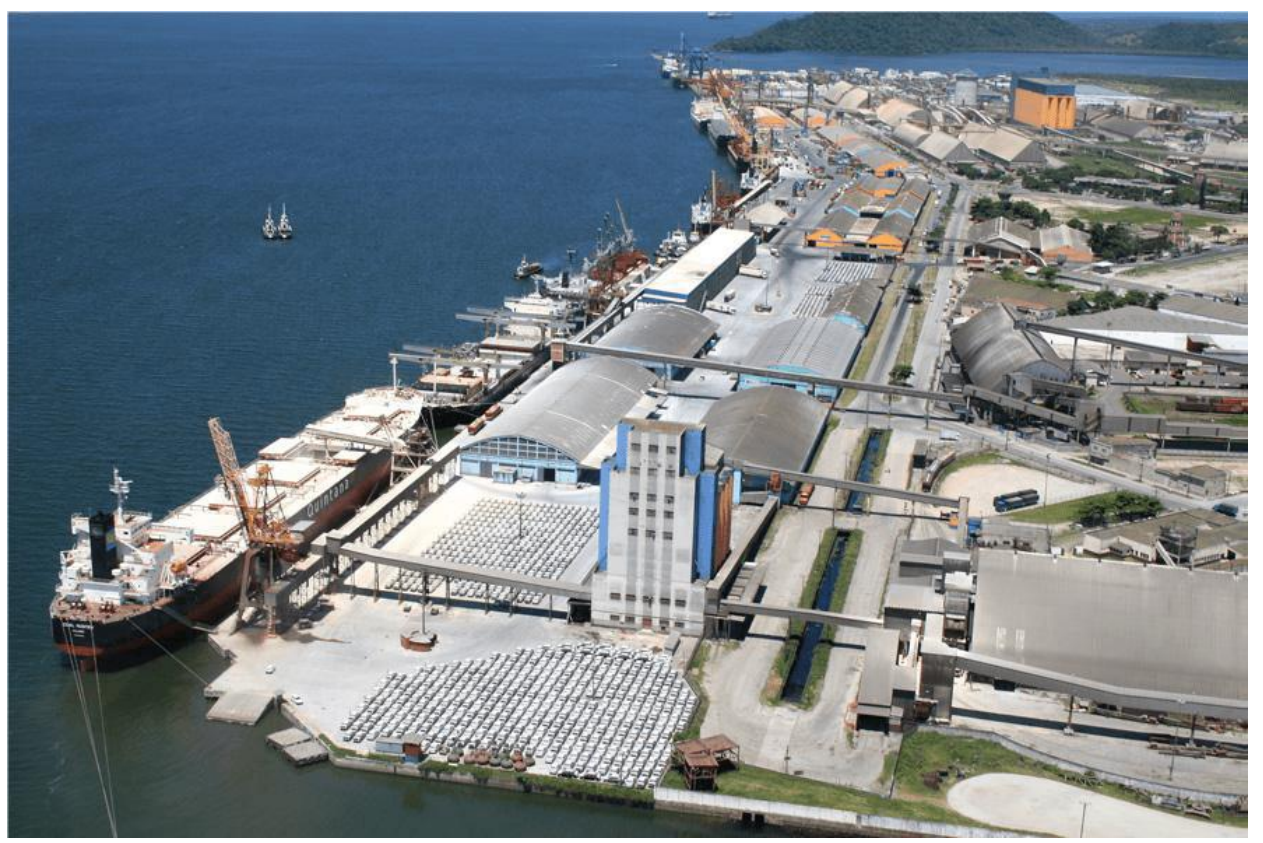

Fonte: ANTAQ (2016). 
De forma a elucidar as perspectivas de como são dispostos a atracação e amarração do porto de Paranaguá, a Figura 2, seguida pela Tabela 1 demonstram a disposição atualizada dos berços, dos piers e dos dólfins utilizados para a operação logística diária.

Figura 2 - Vista aérea dos espaços logísticos do porto de Paranaguá.

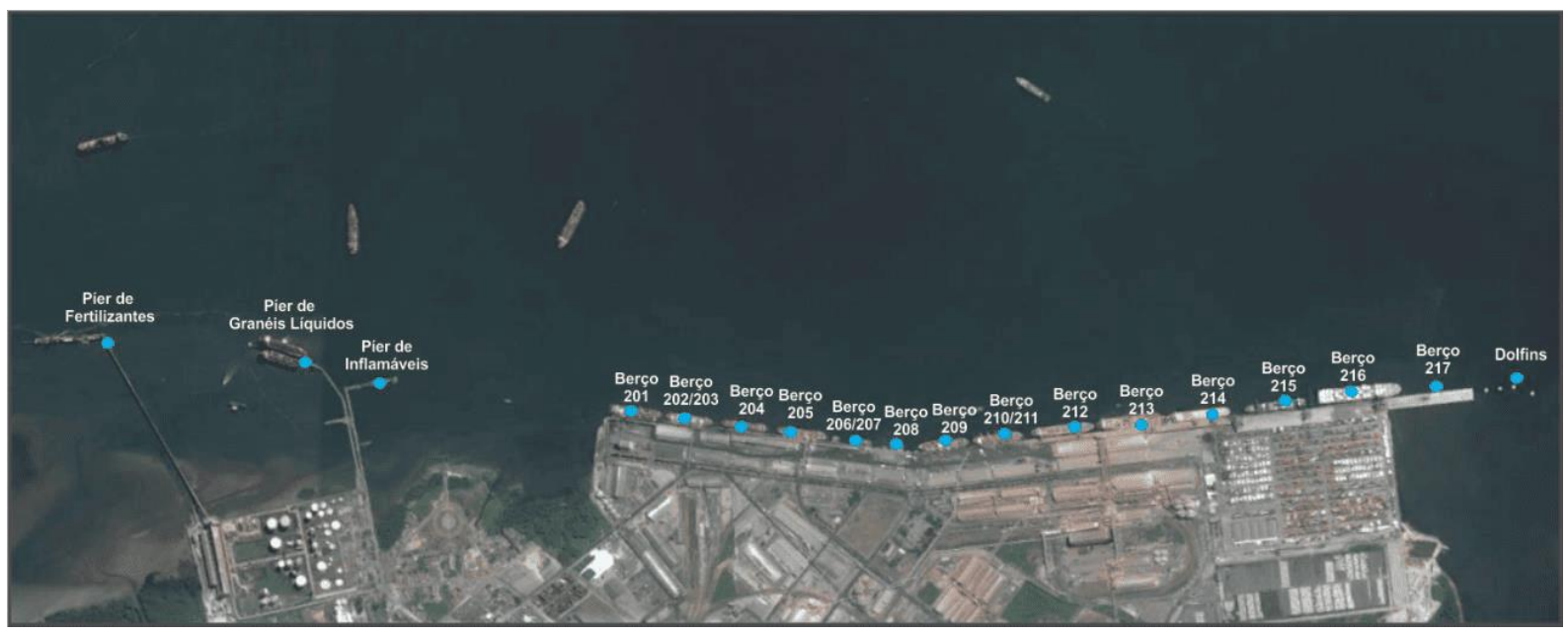

Fonte: Adaptado de Google Maps (2018).

Na Figura 2 é possível visualizar que os berços são dispostos seguidamente, da esquerda para a direita, desde o número 201 ao número 217, finalizado pelos Dolfins de atracação e amarração. No lado extremo esquerdo da Figura 2 é possível identificar - Píer de fertilizantes, seguidos (da esquerda para a direita) do píer de Graneis líquidos e do píer de inflamáveis. Colaborando para uma investigação das destinações, tamanhos e capacidades de cada um destes espaços, a pesquisa traz à lume a Tabela 1.

Tabela 1 - Características dos berços do Caris Comercial do porto de Paranaguá

\begin{tabular}{|l|l|l|l|l|l|l|}
\hline Berço & $\begin{array}{l}\text { Cabeç } \\
\text { os }\end{array}$ & $\begin{array}{l}\text { Comprime } \\
\text { nto }\end{array}$ & $\begin{array}{l}\text { Profundid } \\
\text { ade }\end{array}$ & $\begin{array}{l}\text { Calado } \\
\text { Máximo }\end{array}$ & $\begin{array}{l}\text { Calado } \\
\text { Máximo }\end{array}$ & $\begin{array}{l}\text { Destinaç } \\
\text { ão }\end{array}$ \\
\hline
\end{tabular}




\begin{tabular}{|c|c|c|c|c|c|c|}
\hline & & & & $\begin{array}{l}\text { (sem } \\
\text { espaçador } \\
\text { es) }\end{array}$ & $\begin{array}{l}\text { (com } \\
\text { espaçador } \\
\text { es) }\end{array}$ & \\
\hline 201 & 05 a 12 & 174 & 11 & 10,67 & 11,28 & $\begin{array}{l}\text { Graneis } \\
\text { Sólidos }\end{array}$ \\
\hline $\begin{array}{l}202 / 2 \\
03\end{array}$ & 12 a 20 & 202 & 11 & 10,67 & - & $\begin{array}{l}\text { Carga } \\
\text { Geral }\end{array}$ \\
\hline 204 & 20 a 26 & 163 & 11 & 10,67 & 11,28 & $\begin{array}{l}\text { Graneis } \\
\text { Sólidos }\end{array}$ \\
\hline 205 & 26 a 31 & 154 & 11 & 10,05 & - & $\begin{array}{l}\text { Congelad } \\
\text { os }\end{array}$ \\
\hline $\begin{array}{l}206 / 2 \\
07\end{array}$ & 31 a 39 & 243 & 8,7 & 8,53 & 10,05 & $\begin{array}{l}\text { Graneis } \\
\text { Sólidos }\end{array}$ \\
\hline 208 & 39 a 44 & 152 & 8,7 & - & - & $\begin{array}{l}\text { Carga } \\
\text { Geral }\end{array}$ \\
\hline $\begin{array}{l}209 / 2 \\
10\end{array}$ & 44 a 54 & 241 & 12,7 & - & - & $\begin{array}{l}\text { Graneis } \\
\text { Sólidos }\end{array}$ \\
\hline 211 & 54 a 61 & 176 & 12,7 & 12,3 & 12,3 & $\begin{array}{l}\text { Graneis } \\
\text { Sólidos }\end{array}$ \\
\hline 212 & 61 a 71 & 251 & 12,7 & 12,3 & 12,3 & $\begin{array}{l}\text { Graneis } \\
\text { Sólidos }\end{array}$ \\
\hline 213 & 71 a 81 & 253 & 12,7 & 12,3 & 12,3 & $\begin{array}{l}\text { Graneis } \\
\text { Sólidos }\end{array}$ \\
\hline 214 & $\begin{array}{ll}92 & a \\
107 & \end{array}$ & 335 & 12,7 & 12,3 & - & $\begin{array}{l}\text { Graneis } \\
\text { Sólidos }\end{array}$ \\
\hline 215 & $\begin{array}{ll}92 & a \\
107 & \end{array}$ & 335 & 12,7 & 12,3 & - & $\begin{array}{l}\text { Containe } \\
\text { rs }\end{array}$ \\
\hline 216 & $\begin{array}{ll}107 & a \\
116 & \end{array}$ & 205 & 12,7 & 12,3 & - & $\begin{array}{l}\text { Containe } \\
\text { rs }\end{array}$ \\
\hline 2017 & $\begin{array}{l}\text { Até } 1^{\circ} \\
\text { Dolfin }\end{array}$ & 315 & 13 & 10,3 & 10,3 & $\begin{array}{l}\text { Containe } \\
\text { rs }\end{array}$ \\
\hline
\end{tabular}




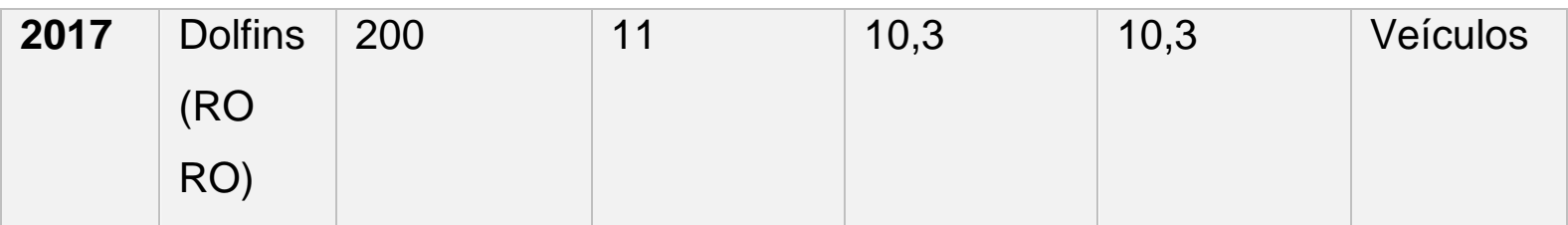

Fonte: Elaborado pelo Autor (2018), com base em APPA (2017).

Identifica-se que há três píeres que podem ser utilizados para o acostamento: 1) inflamáveis; 2) graneis líquidos e; 3) fertilizantes. O primeiro deles, destinado aos inflamáveis, conta dois berços (um interno e outro externo) de 190m cada um e o seu uso público, mas a preferência deste uso é da Transpetro.

Já o píer de graneis líquidos tem uso reservado exclusivamente à Cattalini e dispõe da mesma infraestrutura de dois berços, mas estes com $244 \mathrm{~m}$ cada um. Por seu turno, o píer de Fertilizantes se encontra arrendado à Fospar, com berços interno e externo de $235 \mathrm{~m}$ cada um.

De acordo com as informações da APPA (2017), foi possível elaborara a Tabela 2, que traz evidências e sistematiza o uso dos píeres do porto de Paranaguá, elencando sua destinação, condição, calado máximo, comprimento e localização. Ressalta-se que a leitura da Tabela 2 deve ser realizada em conjunto com a Figura 2, de modo a melhorar a compreensão e entendimento da disposição dos píeres no porto.

Tabela 2 - Características dos berços dos píeres do porto de Paranaguá

\begin{tabular}{|l|l|l|l|l|l|}
\hline Cais & Berço & Comprimento & $\begin{array}{l}\text { Calado } \\
\text { Máximo }\end{array}$ & Destinação & Condição \\
\hline $\begin{array}{l}\text { Cais dos } \\
\text { Inflamáveis }\end{array}$ & Interno & 190 & 11,6 & $\begin{array}{l}\text { Graneis } \\
\text { Líquidos }\end{array}$ & $\begin{array}{l}\text { Arrendado à } \\
\text { Transpetro }\end{array}$ \\
\hline $\begin{array}{l}\text { Cais dos } \\
\text { Inflamáveis }\end{array}$ & Externo & 190 & 10,06 & $\begin{array}{l}\text { Graneis } \\
\text { Líquidos }\end{array}$ & $\begin{array}{l}\text { Arrendado à } \\
\text { Transpetro }\end{array}$ \\
\hline $\begin{array}{l}\text { Píer de } \\
\text { Graneis } \\
\text { Líquidos }\end{array}$ & Externo & 244 & 11,9 & $\begin{array}{l}\text { Graneis } \\
\text { Líquidos }\end{array}$ & $\begin{array}{l}\text { Uso } \\
\text { privativo da } \\
\text { Cattalini }\end{array}$ \\
\hline
\end{tabular}




\begin{tabular}{|l|l|l|l|l|l|}
\hline $\begin{array}{l}\text { Píer de } \\
\text { Graneis }\end{array}$ & Interno & 244 & 7 & $\begin{array}{l}\text { Graneis } \\
\text { Líquidos }\end{array}$ & $\begin{array}{l}\text { Uso } \\
\text { privativo da } \\
\text { Cattalini }\end{array}$ \\
\hline $\begin{array}{l}\text { Píer de } \\
\text { Fertilizantes }\end{array}$ & Externo & 235 & 12 & $\begin{array}{l}\text { Graneis } \\
\text { Sólidos } \\
\text { fertilizantes }\end{array}$ & $\begin{array}{l}\text { Arrendado à } \\
\text { Fospar }\end{array}$ \\
\hline $\begin{array}{l}\text { Píer Interno } \\
\text { Fertilizantes }\end{array}$ & 235 & & 9,2 & $\begin{array}{l}\text { Graneis } \\
\text { Sólidos } \\
\text { Fertilizantes }\end{array}$ & - \\
\hline
\end{tabular}

Fonte: Elaborado pelo Autor (2018), com base em APPA (2017).

Em conformidade com a expansão e importância do porto de Paranaguá para a região em que está alocado, o Plano Mestre do Complexo portuário de Paranaguá e Antonina (MTPA, 2018), documento que emite diretrizes importantes para a modernização dos portos e serve de base para a elaboração do PDZPO, elenca alguns investimentos necessários e traça planos de ações contundentes para que o porto continue crescendo e atenda às necessidades do comércio exterior e local (MTPA, 2018).

Dentre estas melhorias, o Plano Mestre (MTPA, 2018) destaca alguns investimentos portuários necessários, como: modernização dos berços 201 e 202, a ampliação do berço 201; construção do TPPP (Terminal de uso Privado de Pontal do Paraná); expansão do TCP; expansão do terminal de fertilizante da Fospar; resolução do déficit de capacidade para exportação de grãos vegetais e; dragagem de aprofundamento. Estes investimentos foram selecionados pela pesquisa devido ao seu impacto direto operacional na qualidade dos serviços portuários e na agilidade dos serviços, os quais serão analisados detidamente a seguir (MTPA, 2018).

A modernização dos berços 201 e 202, somado à ampliação do berço 201 trará ao porto de Paranaguá mais capacidade de embarque de graneis sólidos, já que atualmente há um déficit neste quesito. Além disso, identifica-se que os equipamentos não estão condizentes com a realidade de modernização do porto de Paranaguá, requerendo trocas para que o efetivo aumento da produtividade ocorra. Assim, a 
implementação da modernização e ampliação destes berços proporcionará ao porto um aumento na capacidade de embarque, modernizando o sistema com dois carregadores de graneis, com capacidade de 2 mil toneladas por hora, aumentado em $100 \mathrm{~m}$ a extensão do cais. Este aumento de produtividade e extensão do cais permitirá que até 3 navios realizem a operação simultaneamente (MTPA, 2018).

O terminal de uso privado de Pontal do Paraná resultará em uma capacidade em acessar o Complexo Portuário por meio marítimo, isso quer dizer que haverá possibilidade de captar os navios que acessam o porto de Paranaguá. A construção de um Terminal de Uso Privado dará á porto uma capacidade significativa em proporcionar mais acessibilidade dos navios ao Complexo Portuário, contemplando uma melhor movimentação de contêineres, o que traz a competitividade necessária ao porto no mercado nacional e internacional. A construção de um Terminal Privado proporcionará ao porto de Paranaguá capacidade de ter um terminar de contêineres com três berços de atracação, dez portêineres, conseguindo satisfazer uma de manda de até 700 mil TEU/ano, já na primeira fase do projeto (MTPA, 2018).

Outro importante fator de expansão para o porto é a obra de modernização no Terminal de Contêineres de Paranaguá (TCP). A correta execução desta modernização trará um aumento na capacidade de movimentação dos contêineres do porto, o que permite a atracar mais embarcações e de maiores portes. Esta possibilidade de atracação de navios maiores traz maior competitividade ao porto, sobretudo no seguimento de contêineres. Basicamente isto consiste em estender o cais, de forma que possibilite a atracação de até três grandes navios de forma simultânea, obras somadas à expansão do pátio em 170 mil $\mathrm{m}^{2}$ para abrigar a armazenagem dinâmica de até 2,5 milhões de TEU (MTPA, 2018).

Também, atualmente há um déficit na capacidade armazenamento dos fertilizantes, o que a longo prazo ocasionará problemas na movimentação da mercadoria. Assim, a imediata modernização deste setor é importante para antever possíveis problemas e resolver os que já estão acontecendo, de modo a não comprometer a competitividade do porto. Para tanto, há necessidade de dragar o berço para que navios maiores sejam permitidos a atracar e a criação de um novo armazém para até 45 mil toneladas de 
capacidade estática. Para dar agilidade ao processo, a construção de um sistema de correias de transporte que ligam o cais á retro área deve ser duplicada para que a capacidade de movimentação deste terminal passa para 3 milhões de tonelada anuais (MTPA, 2018).

Ainda no que tange aos problemas estruturais de capacidade, há necessidade de que o porto de Paranaguá realize obras em seu Complexo para sanar o déficit de capacidade para exportação de grãos vegetais, para não ver sua competitividade de exportação internacional comprometida. Para este ponto, pode-se sanar a situação com a construção do Píer em 'T' do COREX e do Píer em 'F' do Novo Corredor de Exportação Oeste, o que aumentaria a capacidade do complexo portuário para a movimentação destes grãos vegetais para a exportação, reestabelecendo a competitividade internacional.

Com a execução destas obras de infraestrutura será possível aumentar a movimentação de graneis para 16 mil toneladas por hora no píer em ' $F$ ', distribuídos em quatro novos berços, e para 16 mil toneladas por hora no píer em ' $T$ ', estes também em quatro novos berços com um sistema de oito correias de transporte dos grãos das esteiras diretamente aos navios (MTPA, 2018).

Outro importante aspecto para trazer e manter a competitividade internacional do comercio exterior ao porto de Paranaguá diz respeito aos métodos e campanhas constantes de dragagem. Este processo proporciona que navios maiores possam atracar ao porto, o que significa que a capacidade de atuação no mercado também aumenta, tanto para importação, quanto para exportação. Assim sendo, projetos constantes de dragagem e aprofundamento do canal são sobremaneira importantes para a competitividade, para o aprofundamento do canal de acesso, da bacia de evolução e dos berços do Porto Organizado, além de melhorias na sinalização e balizamento.

Calcula-se que o volume a ser dragado é de aproximadamente 14 milhões de metros cúbicos, englobando as áreas que dão acesso ao canal e às bacias de evolução do porto de Paranaguá. A área Alfa, que conta atualmente com 200 m de largura, passará 
a ter 250 m com a dragagem, já as áreas Bravo 1 e Bravo 2 passarão de 150 m para $200 \mathrm{~m}$ de largura (MTPA, 2018).

Ante ao exposto e observado pela pesquisa como forma de recuperação da competividade do comercio exterior do porto de Paranaguá, a pesquisa sistematizou as informações de investimentos na Tabela 3.

Tabela 3 - Resumo de Investimentos portuários

\begin{tabular}{|c|c|c|c|}
\hline Descrição & Instalação & Responsável & $\begin{array}{l}\text { Prazo } \\
\text { recomendado* }\end{array}$ \\
\hline $\begin{array}{l}\text { Modernização dos berços } 2012 \\
\text { e } 202\end{array}$ & $\begin{array}{l}\text { Porto de } \\
\text { Paranaguá }\end{array}$ & APPA & 5 anos \\
\hline Construção do TPPP & $\begin{array}{l}\text { Complexo } \\
\text { Portuário }\end{array}$ & TPPP & 5 anos \\
\hline Expansão do TCP & $\begin{array}{l}\text { Porto de } \\
\text { Paranaguá }\end{array}$ & TCP & 5 anos \\
\hline $\begin{array}{l}\text { Expansão do terminal de } \\
\text { fertilizantes }\end{array}$ & $\begin{array}{l}\text { Porto de } \\
\text { Paranaguá }\end{array}$ & Fospar & 5 anos \\
\hline $\begin{array}{l}\text { Déficit de capacidade de } \\
\text { exportação de grãos vegetais }\end{array}$ & $\begin{array}{l}\text { Porto de } \\
\text { Paranaguá }\end{array}$ & APPA & 5 anos \\
\hline $\begin{array}{l}\text { Dragagem de aprofundamento } \\
\text { (canal de acesso, bacia de } \\
\text { evolução e berço público). }\end{array}$ & $\begin{array}{l}\text { Complexo } \\
\text { Portuário }\end{array}$ & APPA & 5 anos \\
\hline
\end{tabular}

Fonte: Elaborado pelo Autor (2018), com base em MTPA (2018).

De acordo com as informações do último relatório emitido pela Gestão da Administração dos Portos de Paranaguá e Antonina (APPA, 2018), que compreende uma análise dos anos de 2011 a 2017 das feitorias de infraestrutura e modernização realizadas pela entidade em ambos os portos. O relatório traz evidências, sob o ponto 
de vista da APPA (2018), quais investimento foram realizados e de que forma estes tiveram impactos na competitividade portuária dos portos.

De acordo com o Caderno de Resultados (APPA, 2018) o Porto de Paranaguá é o primeiro em exportação de farelo de soja e óleo vegetal do país, ocupando o segundo lugar em exportação de açúcar, milhos, algodão, papel, álcool e veículos e terceiros lugar no ranking nacional na exportação de congelados, soja e madeira. Em contrapartida, o porto se encontra em primeiro lugar nas importações de fertilizantes, em segundo nas de pastas e outros produtos químicos e em terceiros lugar no quesito importação de graneis sólidos, máquinas, peças e equipamentos (APPA, 2018).

Ainda de acordo com o relatório, em conformidade com os dados apurados no PDZPO (2017), a APPA informa que em 2019 haverá 16 metros de profundidade no canal, em decorrência das dragagens e com isso 25 navios poderão ser atendidos de forma simultânea. Com isso, o porto de Paranaguá passa a ter 3.511 metros de cais comercial e berços e com comprimento entre 225 e 440 metros. Estes avanços tecnológicos e de melhorias de infraestrutura proporcionam ao porto uma maior competitividade internacional em suas exportações, fazendo-o polo de negócios, o que pode ser evidenciado pela quantidade de movimentação de cargas em 2017, conforme Gráfico 2.

Gráfico 2 - Evolução de movimentação de carga (em milhões de toneladas).

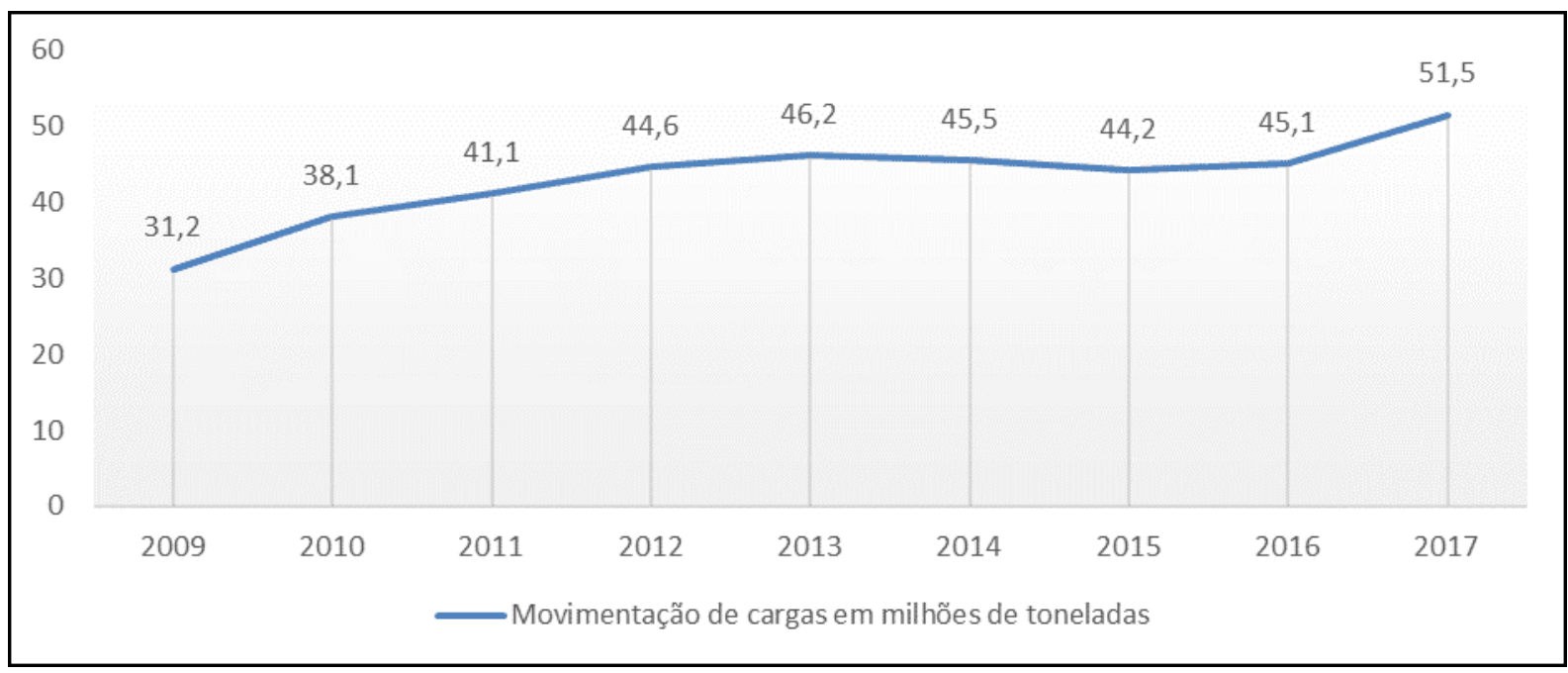

Fonte: Elaborado pelo Autor (2018), com base em MTPA (2018). 
Embora a evolução não tenha se apresentado consistente, apresentando uma baixa nos anos de 2013 a 2015, com as iniciativas administrativas o porto saltou para 51 milhões de toneladas movimentadas, um numero que the rendeu um recorde nacional neste seguimento, representado por esse aumento de $14 \%$ em relação ao ano de 2016. Destas exportações, 9,3 milhões de toneladas são de carga geral; 7,6 milhões de toneladas de graneis líquidos e; 34,3 milhões de toneladas de graneis sólidos, o mais expressivo dos numerários (APPA, 2018).

Ainda de acordo com os dados informados pelo Caderno de Resultados 2018 disponibilizado pela APPA, algumas ações, além daquelas modernizações estruturantes já tratadas anteriormente, são responsáveis pela modernização do porto e pelo avanço competitivo das exportações do porto de Paranaguá pode-se extrair as seguintes:

1. Expansão e complementação do sistema de segurança pública portuária;

2. Construção de novas portarias e novas balanças;

3. Construção de novo prédio para os setores de segurança e administração dos portos de Paranaguá e Antonina;

4. Nova iluminação nas áreas e nos pátios de manobras;

5. Construção de nova subestação e recuperação da rede elétrica;

6. Aquisição de carregadores de navios (shiploaders);

7. Novo sistema de prevenção e combate a incêndio;

8. Aquisição e instalação de cercas de construção de calçadas, visando maior proteção das áreas de carga;

9. Obras de ampliação do sistema de descarga de graneis do silo público;

10. Melhoria da infraestrutura viária.

Espera-se que com as melhorias o Complexo Portuário consiga aumentar sua capacidade e atender à demanda crescente de exportações e importações, tanto regional, quanto nacional. O porto de Paranaguá tem sido referência em sua área de atuação e vem conquistando algumas melhorias constantes em sua infraestrutura, contudo ainda são necessárias algumas outras para que, de fato, a competitividade 
se estabeleça e as exportações continuem crescendo de forma continua e consistente, sem sobressalto.

A projeção é que em 2030 a movimentação de cargas no Paraná atinja o nível de 83 milhões de toneladas, ou seja, quase $40 \%$ mais movimentação em relação aos 50 milhões de toneladas movimentadas no ano de 2017. Assim, a expectativa da APPA (2018), é de que os portos do Paraná, em conjunto, consigam movimentar uma média de 20 milhões de toneladas ao ano cada um.

Infraestrutura não se constrói de uma hora para a outra. O trabalho para destravar o gargalo histórico que o Brasil tem nesta área tem de ser eficiente. Por outro lado, é preciso planejar o crescimento da demanda logística para as próximas décadas, para que este problema seja sanado no futuro. Pensando nisso, em 2012 foi elaborado o Plano de Desenvolvimento e Zoneamento do Porto Organizado de Paranaguá e Antonina. O documento estabelece uma previsão de movimentação de cargas nos portos do Estado para os próximos 20 anos e, desta forma, passa a guiar o planejamento estratégico do porto desde já (APPA, 2018, p. 119).

As ações da APPA, principal ente responsável pela evolução do porto de Paranaguá e Antonina, desempenha papel fundante para que a manutenção e evolução portuária do Paraná continue sobressalente no ambiente competitivo mundial. A responsabilidade com que se trata a perspectiva dos portos brasileiros é primordial na tomada de decisões, pois, como visto, são necessárias ações constantes e diuturnas para que seus reflexos sejam percebidos a um médio e longo prazo.

Além disso, são necessários investimentos constantes em modernização portuária, para que a infraestrutura não se torne deficitária e continue a atender às necessidades das empresas que do porto fazem uso. Um porto modernizado, com uma administração coerente, com vias ao futuro, faz com que o gargalo econômico de escoamento de produção se reduza, proporcionando maior competitividade internacional do comercio, sobretudo do Paraná. 


\section{CONSIDERAÇÕES}

A pesquisa conseguiu investigar o histórico do porto de Paranaguá e como o seu impacto econômico afeta diretamente a cidade e, consequente, o estado do Paraná. Foi possível entender de que forma a tecnologia e a modernização implementada pela administração do porto contribui para que os resultados atuais fossem conquistados e alguns recordes fossem atingidos, ainda que a infraestrutura não seja a ideal.

A pesquisa identificou que o porto de Paranaguá tem déficit em alguns aspectos operacionais do escoamento da produção e que, se saudados, a médio e longo prazo conseguirá atingir os objetivos traçados pelo Plano Mestre de dobrar a sua capacidade de movimentação. Em conformidade com o PDZPO, o porto tem implementado políticas voltadas à sua modernização, de forma a maximizar a capacidade do Complexo Portuário e a competitividade do escoamento da produção.

Outrossim, o PDZPO traça diretivas claras ao crescimento sustentável do porto de Paranaguá que, se corretamente implementadas, podem contribuir para atingir o objetivo final de 83 milhões de toneladas movimentadas por ano, até 2030. Neste contexto as ações implementadas pelo PDZPO no que concerne ao desenvolvimento da infraestrutura portuária são suficientes para que a capacidade de movimentação seja reestabelecida gradualmente e, posteriormente, consiga ganhar produtividade e competitividade no cenário internacional.

As melhorias apontadas, tanto pelo PDZPO e pelo Plano Mestre, quanto pelo Caderno de Resultados são ímpares para um Complexo Portuário em franco crescimento, com padrões de qualidade altamente estabelecidos e que contribuam para promover o país um cenário mundial. Ao promover o cenário em um cenário mundial, o estado do Paraná é automaticamente guinado a um patamar de destaque no contexto nacional de exportações, o que o beneficia sobremaneira em relação aos investimentos públicos de vários setores, inclusive o próprio setor portuário.

A modernização do porto de Paranaguá viabiliza a movimentação de cada vez mais mercadorias, de modo que consiga receber navios cada vez maiores e sua produção 
aumente gradativamente. Com a sua produção maior, o comércio exterior tende a ser alavancado, pois o porto se torna referência em escoamento de produção, puxando investimento e empresas para sua área de atuação, atraídos pela sua infraestrutura e consistente crescimento.

Assim sendo, a modernização e o desenvolvimento da infraestrutura dos píeres e berços de atracação do porto de Paranaguá contribui para o comércio exterior do estado do Paraná somente se a administração portuária continuar os investimentos sólidos nesta demanda, almejando alcançar os objetivos de maximização de capacidade de médio e longo prazo. Apenas uma administração de visão, que tenha olhos no futuro de Paranaguá conseguirá realizar um trabalho que persista, pois, as obras necessárias para que o porto ganhe competitividade em sua capacidade de movimentação de mercadoria não são construídas rapidamente, tampouco sem um planejamento financeiro estruturado.

Para as próximas pesquisas, recomenda-se um estudo de campo a fim de medir in loco quais as percepções de funcionários, usuários e empresas que fazem parte do Complexo portuário para, de fato, comprovar se as informações de investimento e implementação de infraestrutura acontecem e se são suficientes para a vazão atual e futura dos produtos comercializados. Também, é recomendado que os dados aqui elencados como pendentes de execução sejam fiscalizados e comparados para verificar se foram executados e, sobretudo, se trouxeram os benefícios que eram esperados.

Portanto, o estudo contribuiu para entender que são necessários investimentos consistentes, a médio e longo prazo, para que o porto de Paranaguá ganhe competitividade no cenário internacional de comércio exterior, alavancando o país no cenário internacional e, consequentemente, alavancando-se como referência nacional de infraestrutura e modernização portuária. Outrossim, salienta-se que o porto de Paranaguá atualmente tem preponderante importante relevância econômica, social e cultural à cidade de Paranaguá, ao estado do Paraná e ao Brasil, resguardadas as devidas proporções de cada esfera, já que desde sua concepção determina como as relações de consumo e sociais se darão em face de seu desenvolvimento e 
crescimento. Assim, é imprescindível que o porto continue crescendo, não apenas para a sua competitividade internacional, para a manutenção de todo o seu entorno.

\section{REFERÊNCIAS}

ABRAHÃO, C. M. (2011). Porto de Paranaguá: transofrmação espacial decorrentes do processo de modernização capitalista e integração terriotrial entre os anos 1970 e 2010. (Tese em Geografia) Universidade Federal do Paraná, Curitiba.

ANTAQ. (2009). Definições de termos e conceitos técnicos utilizados neste anuário. Acesso em 30 de set. de 2018, disponível em ANTAQ: http://antaq.gov.br/Portal/Anuarios/Portuario2009/termos.htm

APPA. (2018). Caderno de Resultados: 2011-2017. Acesso em 01 de dez. de 2018, disponível em Adminsitração dos Portos de Paranaguá e Antonina: http://www.portosdoparana.pr.gov.br/arquivos/File/Caderno_resultados_APPA_2018 1.pdf

CALADO, A. (2015). Mundo Naval: Navios Ro-Ro. Acesso em 30 de set. de 2018, disponível em Jornal Canal 16: http://jornalcanal16.com.br/jornal-2015/mundo-naval3-navios-ro-ro/

GIL, A. C. (2013). Métodos e Técnicas de pesquisa social (6 ed.). São Paulo: Atlas.

GODOY, A. M. (1998). Um olhar sobre a cidade de Paranaguá: os impactos sócioambientais das mudanças portuárias. (Tese de Meio Ambiente e Desenvolvimento) Universidade Federal do Paraná, Curitiba.

GOOGLE MAPS. (2018). Porto de Paranaguá. Acesso em 10 de nov. de 2018, disponível em Google Maps: https://www.google.com.br/maps/@-25.4984584,$48.5209835,3978 \mathrm{~m} / \mathrm{data}=! 3 \mathrm{~m} 1 ! 1 \mathrm{e} 3$

HARVEY, D. (2005). A produção capitalista do espaço. São Paulo: AnnaBlume. 
KEEDI, S. (2017). Logística de transporte internacional: veículo prático e competitivo (2 ed.). São Paulo: Aduaneiras.

KOJIKOVSKI, G. (2017). Além de toda a insegurança política, o Brasil continua a jogar contra seus empresários quando o assunto é abertura comercial. Acesso em 19 de nov. de 2018, disponível em Exame: https://exame.abril.com.br/economia/brasilcampeao-de-isolamento/

LUNA, E. P. (2015). Essencial de comércio exterior de $A$ a $Z$ (2 ed.). São Paulo: Aduaneiras.

MARCONI, M. D., \& LAKATOS, E. M. (2017). Técnicas de pesquisa: planejamento e execução de pesquisas, amostragens e técnicas de pesquisas, elaboração, análise e interpretação de dados (8 ed.). São Paulo: Atlas.

MTPA. (2018). Plano mestre do Completo Portuário de Paranaguá e Antonina. santa Caratina: UFSC.

MTPA. (2018). Plano mestre porto de Paranaguá. Acesso em 01 de dez. de 2018, disponível em Ministério dos Transportes, Portos e Aviação Civil: http://www.portosdobrasil.gov.br/assuntos-1/pnpl/arquivos/planos-mestres-sumariosexecutivos/se22.pdf/@@download/file/se22.pdf

PDZPO. (2017). Plano de desenvolvimento e zoneamento do porto de Parabaguá. Acesso em 01 de dez. de 2018, disponível em Administração dos Portos de Paranaguá e Antonina: http://www.paranagua.pr.gov.br/imgbank2/file/plano_diretor/revisao/propostas/1.\%20 PDZ\%20Porto\%20de\%20Paranagu\%C3\%A1.pdf

PRODANOV, C. C., \& FREITAS, e. C. (2013). Metodologia do trabalho cientifico: métodos e técnicas da pesquisa e do trabalho acadêmico (2 ed.). Novo Hamburgo: Freevale. 
SCHEIFFER, B. (2008). Paranaguá, cidade portuária: entre a cidade sonhada e a cidade real. (Dissertação em História) Universidade Estadual do Oeste do Paraná, Marechal Cândido Rondon.

SEVERINO, A. J. (2007). Metodologia do trabalho científico (23 ed.). São Paulo: Cortez.

SOUSA, M. A. (2016). Logística de containers: um diferencial competitivo para dminuir os custos operacionais no varejo de material de construção no trecho Santos-Manaus. (Dissertação) Universidade Federal do Pará, Belém.

TAVARES, A. C. (2013). O porto de Naal: sua importãncia para o comercio exterior do RN. (Monografia em Engenharia e Gestão Portuária) Universidade Federal de Santa Catarina, Florianópolis.

TRINTIN, J. G. (2001). A economia paranaense: 1985-1998. (Tese em Ciências Econômicas) Universidade Estadual de Campinas, Campinas.

YIN, R. K. (2011). Estudo de caso: planejamento e métodos (3 ed.). Porto Alegre: Bookman.

4. "Traduzindo ao pé da letra, Roll-On/Roll-Off significa "Rolar para dentro/Rolar para fora". A principal característica desse tipo de embarcação é o transporte de cargas que se movem por meio de rodas. Ele é mais conhecido como navio Ro-Ro, um acrônimo da palavra Roll-On/Roll-Off" (CALADO, 2015, online).

5. "Coluna de concreto fincada no fundo do mar que aflora à sua superfície e serve para atracar (dólfim de atracação) e para amarrar (dólfim de amarração) navios. Em alguns casos dispensam os cais corridos" (ANTAQ, 2009).

Enviado: Setembro, 2019.

Aprovado: Outubro, 2019. 